\title{
Young People, the Internet, and Civic Participation: An Overview of Key Findings from the CivicWeb Project
}

\section{Shakuntala Banaji}

London School of Economics

s.banaji@lse.ac.uk
David Buckingham

Centre for the Study of Children, Youth, and Media, Institute of Education, University of London D.Buckingham@ioe.ac.uk
Visit IJLM.net

\section{doi:10.1162/ijlm_a_00038}

(C) 2010 Massachusetts Institute of Technology

Published under Creative Commons Attribution-Noncommercial-No Derivative Works 3.0 Unported license

Volume 2, Number 1

\section{CivicWeb: Background and Rationale}

Over the past two decades, concern about an apparent decline in civic and political participation has been widespread across Europe and in many nonEuropean industrialized countries. Commentators point to long-term reductions in voting rates, declining levels of trust in politicians, and waning interest in civic affairs, and these phenomena are frequently seen as evidence of a broader crisis in democracy (e.g., Putnam 2000; Scheufele and Nisbet 2002; Gibson, Nixon and Ward 2003; Galston 2004). These characteristics are generally seen to be most apparent among the young: it is often asserted that young people are increasingly apathetic and reluctant to exercise their civic responsibilities. In this context, some have looked to new media-and particularly the Internetas a means of reengaging young people and thereby of revitalizing civic life. The Internet is seen to have greater appeal and relevance for young people than do "older" forms of civic participation and is seen to have the potential for creating new, networked forms of communication and democratic political culture (Bennett 2003; Lenhart, Fallows, and Horrigan 2004; Coleman 2005, 2008; Zukin et al. 2006; Kann et al. 2007). In addition to generating considerable enthusiasm among policymakers, these possibilities have been addressed by growing numbers of researchers in recent years (e.g., Dahlgren 2007; Gerodimos 2008; Loader 2007; Bachen et al. 2008; Bennett 2008; Bennett, Wells, and Freelon 2009).

We set out to test these arguments with CivicWeb, a three-year research project funded under the European Commission's Framework 6 program for targeted socioeconomic research. With CivicWeb we sought to analyze the potential contribution of the Internet to promoting civic engagement and participation among young 
people (ages 15-25). The project took a broad view of the Internet but focused on the range of youth-oriented civic sites now emerging on the World Wide Web. These sites are created by many organizations, interest groups, and individuals, and they range from smallscale, local initiatives to national and international projects.

We used both quantitative and qualitative methods and focused on three key dimensions of the new online civic sphere:

- the nature and characteristics of such sites-that is, their content and formal features (design, mode of address, structure) and the extent to which they invite active participation from their users;

- the production of the sites, including the motivations, working practices, and economic models of the producers; and

- the uses and interpretations made of such sites by different social groups of young people and the relationship between this online activity and their civic participation offline.

In framing our research, we adopted a deliberately broad and open conception of "civic participation." The kinds of sites and activities we examined include:

- initiatives on the part of government (including the European Union) or political parties (e.g., via such parties' youth wings) to secure greater civic participation;

- initiatives based on single-issue campaigns (e.g., around globalization, discrimination, opposition to hunting, and homelessness);

- more open forums in which young people from particular social groups (the disabled, refugees, gays and lesbians) come together to define and debate their own agenda of issues;

- sites promoting social activity or participation based on religious beliefs;

- sites encouraging volunteerism and social activism;

- $\quad$ sites designed for specific ethnic minorities or geographically isolated groups; and

- $\quad$ sites addressing areas that might be seen as problematic, such as political violence or xenophobic hatred.

Potentially, these sites and activities constitute a powerful form of nonformal learning: they can promote the development of social capital and create new forms of political, social, and economic participation.
Yet their effectiveness in doing so is likely to depend on the offline social and political context in which they are situated. Our research therefore explored the different ways in which the civic potential of the Internet varies across the different political cultures of seven European member states or applicant nations: Hungary, the Netherlands, Slovenia, Spain, Sweden, Turkey, and the United Kingdom. The partner countries represent different cultural and political histories, different political systems, and different relationships with the European Union. Our aim was to identify some of the issues and dilemmas faced by practitioners and policymakers in relevant fields and to understand some of the key characteristics of good practice. We also sought to consider how information and communication technologies-and these civic sites in particular-might be used in the context of citizenship education, not least in developing more participatory and self-actualizing approaches to civic learning.

In exploring this emerging phenomenon, several empirical questions needed to be addressed. Can the Internet in fact deliver on the promise of reengaging young people in the public sphere and of creating new forms of political and civic culture among young people? How far does participation online result in greater participation offline in the field of civic culture? Are some kinds of young people (e.g., as defined in terms of social class, gender, ethnicity, religion, or culture) more likely to respond to such invitations than others? Are some groups more likely to stay within more traditional forms of civic participation or to resist them altogether? What are the obstacles to such new media initiatives, and how can we distinguish between good and bad practices in this field? How well does the model of "networked citizenship" correspond to the everyday practices and motivations of the majority of young people? Do these virtual networks constitute new forms of civic participation in themselves? And how do these developments vary across the different political cultures of European member states? These are among the questions that CivicWeb sought to address.

\section{Methods}

Our approach involved several distinct but overlapping forms of investigation that were described in a series of reports as the research proceeded (see http:// www.civicweb.eu/). We began by reviewing existing research and considering the different ways in which 
our key questions and concepts had been addressed across the different participating countries. We found that the terminology being used in this debate is not consistent or transparent: words like civic, political, citizenship, democracy, and engagement can mean quite different things in different contexts.

Bearing in mind the inherently slippery nature of these terms, we set out to map the range of civic websites available for young people in the seven countries. Like the early reports produced in the United States by Kathryn Montgomery and her colleagues (2004), our study at this point was largely descriptive, involving the selection and classification of approximately 50 civic/political websites and 30 youth-specific sites in each country, for a total of 560 sites. These were categorized in terms of their topic, stated purpose and aims, use of applications, layout, interactivity, network features, and mode of address, as well as their pedagogic and ideological outlook. While the analysis here was primarily qualitative, it did include some quantitative aspects-for example, in relation to the numbers of interactive applications or the proportion of calls for online versus offline participation.

We then developed in-depth case studies of a range of civic websites (six to eight in each country), looking further at the interconnections between pedagogy, design, mode of address, ideological stance, and the aims of the site in the context of specific national historical and social circumstances. Case studies from different countries were then compared under the following categories: party political sites; European-wide youth sites; youth activist sites; general (adult and youth) activist sites; sites promoting civic participation more broadly; sites promoting volunteering; youth council sites; sites addressing specific identities (minority, regional, national); and youth counseling sites.

Overlapping with the survey of websites and the case studies was a series of in-depth interviews with the producers of civic websites in each partner country $(n=85)$. Here, too, we attempted to sample producers from a range of organizations and contexts, from national and local governmental bodies and large NGOs through to grass-roots youth activists. Our aim was to gain an understanding of how the producers view their sites; why they have a website, what its purpose is, and how it links to offline activities; how they came to decisions about their site's design; how they perceive their site's audience and/or participants; and how they conceptualize the interlinked civic and political spheres.
In considering the users (or potential users) of these sites, we set out to provide a broad survey alongside in-depth qualitative analysis. We conducted an online questionnaire with over 3,300 participants in the seven participating countries. The survey provided basic quantitative data about young people's uses of the Internet and the extent to which they were engaging in civic activities both online and offline. This was followed by a series of in-depth focus group interviews with young people: $10-12$ such groups were convened in each country, covering a range of demographic groups and involving young people who were civically active and inactive, Internet-savvy and Internet-excluded, as well as educationally disadvantaged or socially excluded. These groups enabled us to explore the young people's Internet practices within different sociocultural contexts, their motivations for political and/or civic engagement and how the Internet helped them to pursue their interests in these areas, their responses to civic content online, and the role of civic and/or political education.

Reports from each of these investigations are available online, and specific case studies or aspects of the research are reported in some of the other articles in this issue of IJLM. Our aim in the present article is to provide an overview of some of the key themes that have emerged from the project and to raise broader critical questions. In doing so, we seek to illustrate some of the relationships and interconnections-but also some of the contradictions and fault lines-between the different elements of the study and the extent to which these reflect broader historical and national trends in civic and political participation among young people.

\section{Toward Empowerment?}

In general, our research supports the view that young people are mostly alienated, or at least disconnected, from traditional forms of politics and civic participation. Most of the focus group respondents across all our national samples said they saw politicians as corrupt, boring, or hard to understand; working only for their own interests; and far removed from the everyday needs and realities of common citizens. A large proportion of respondents felt that things needed to change, and they spoke, often at length, about such issues as inequality; corruption; lack of housing and job opportunities; high prices; religious, ethnic, or regional discrimination; police harassment of civil protest; and 
government censorship of the media. Respondents generally felt that they themselves were unable to change these things. This perceived lack of efficacy was often related to their general feelings about the unresponsiveness, untrustworthiness, and distance of politicians. However, the feeling also derived from respondents' actual experiences of having participated (e.g., in school councils, e-petitions, or demonstrations) and of not having been listened to or not managing to change anything. In some instances, their feeling also related to fears about how active participation or political critique might impact them as individuals and make them targets of the state, the police, or aggressive citizens with opposing views.

For many of the Web producers we interviewed, this perceived lack of efficacy was the central problem. The rhetoric of "youth empowerment" and "youth voice" was particularly prominent here. These discourses typically see young people as lacking a voice, or at least the skills to make their voices heard: when they are given a voice online, the argument goes, they will be empowered to express their own concerns in a safe environment, and this empowerment can then be transferred offline to provide them with greater control of their own lives. While some producers saw this as a more-or-less spontaneous consequence of gaining access to technology, many working within activist and/or charitable organizations felt that young people should have more opportunities and training to help them develop the skills necessary for making their voices heard in the public sphere. Ironically, however, many of these producers were aware that their users tended to be mostly those youth who were already engaged or skilled in civic participation. The challenge for all concerned was to find ways of reaching "hard to reach" and disadvantaged young people, those most at risk of exclusion from civil society and politics. The Internet has, thus far, not been found to be a particularly good means of doing this, and traditional offline approaches involving youth workers and local youth groups are still the main points of contact for economically and socially disadvantaged young people.

These perceptions were reinforced by the findings of our research with young people. Unsurprisingly, we found that social factors such as class, ethnicity, age, and religion significantly affected the ways in which young people approached and used the Internet. In our survey, the interest in civic and political websites appeared to be stronger among older respondents
(19- to 25-year-olds rather than 15- to 18-year-olds), those not living with their parents, youth who identified as religious, and girls and young women. This contradicts some commonly held perceptions-for instance, that girls and young women are less motivated to participate politically than are boys and young men. However, the factor showing the clearest patterns in relation to Internet use and civic participation across most of the countries was that of socioeconomic class. We found evidence of a continuing digital divide along socioeconomic lines, both in the quality and extent of access to technology and in the extent of civic engagement.

The Internet appeared to be an important tool for young people who were already engaged in civic or political activities offline. In focus groups with young people who were active in global or local political, religious, or identity-based groups, the Internet was consistently presented as a major hub for political activities. This appeared to be the case for groups as diverse as political parties' youth organizations, various kinds of established activist networks, and communities of civic interest. The Internet was also an important resource for minorities-political, sexual, ethnic, regional, or religious-and, in some notable instances, seemed to offer young people from such communities a space to question and enact identity, to question notions of tradition, to discuss the meaning of culture and citizenship, or to debate methods of participation and protest (see Szakács and Bognár 2010 in this issue of $I J L M$ ).

However, the content and loci of the discussions that do take place online should not be homogenized. The respondents to our survey were overwhelmingly interested in websites on entertainment and lifestyle issues: only a small proportion (around 10 percent) reported having visited civic or political sites. This does not necessarily mean that they have not participated in civic discussions online, however, because evidence suggests that such discussions (between people of all ages) may be found in the forums of entertainment and social networking sites of various kinds. Furthermore, not all young people who are civically active offline participate in such discussions online, and the ones who do participate online may do so only sporadically.

\section{Using the Internet}

The Internet seems to be regarded by a number of civic and political organizations as an inexpensive 
and effective method of disseminating information and making contact with young people. However, our research suggests that this strategy is by no means always inexpensive or as effective as offline mobilization. Several producers pointed out that for a site to be known, considerable thought must be given to marketing and publicity. Most civic website producers have neither the time nor the money to publicize their sites adequately, and hence the core of users remains relatively small. Indeed, a majority of the websites surveyed across the project functioned with a combination of one or two part-time paid employees and several volunteer staff. Some sites went for months without being updated because initial grants funded only the building of the site and not its maintenance, which is crucial to success. We found high turnover rates among volunteer staff at the real or virtual offices of many of the civic websites surveyed, and turnover sometimes led to the closure of a site. The sites themselves thus have a high attrition rate, and the picture for any one site can change rapidly from one year to the next.

Despite the availability of more-or-less interactive applications such as blogs, wikis, message boards, forums, video uploading, podcasts, and so on, static websites composed primarily of written text and a few visual images still appear to be the norm. Of ten interactive applications we chose to look for, most youth civic websites in our larger survey offered only an average of 2.5 (and most commonly these included photographic content and embedded YouTube videos). The possibility for young people to post their own content or to question content on the sites was rare. However, the issue of interactivity on youth civic sites is not straightforward. Some funders appear to think that complex and more expensive sites are always and automatically better than their simpler counterparts. However, our interviews with producers and with young people suggest this is by no means always the case. Offering interactive facilities does not automatically mean that young people will participate. We found several instances of websites that have forums, user content upload facilities, and message boards on general themes (relating to European or more global issues) that were underused or full of spam.

Claims about the Internet being a completely safe and equal space for participation were also challenged by a number of responses from both producers and users of civic websites. Several producers were aware that dealing with controversial issues of social justice could provoke strong and negative responses from some members of the public. Some young people described being "attacked" online, a phenomenon that was particularly apparent with sites concerned with sexuality and, in the case of Sweden, gender. In the Netherlands and the United Kingdom, young first- and second-generation immigrants are forming civic organizations online to challenge prejudice both within and outside their communities. Many of these immigrants are subjected to fierce and sometimes racist online critique and flaming, often by organized right-wing groups. In Hungary, Roma sites attempt to avoid this situation by having closed membership or by censoring posts from racist users (see Szakács and Bognár 2010).

Forums, user-generated content, and other interactive applications have to be carefully explained, encouraged, motivated, and managed. Young people are sometimes as intimidated by what they view as a "requirement" to contribute original content as they are disappointed by the lack of possibilities for commenting or interacting online. Specialized jargon has to be avoided or explained. The skills for using applications such as RSS feeds, videocasts, or podcasts have to be taught rather than being taken for granted. This requires planning, time, and money for personnelresources that most of the youth civic organizations surveyed simply do not have. Several of the producers we interviewed felt that a clear, helpful, but static site that allowed youth to email the organization was better than offering potentially off-putting or even damaging opportunities for "interaction."

Yet paradoxes remain, as Fabbro's (2010) study in this issue of IJLM suggests. Although most producers still see the importance of promoting their organization or activities through traditional media channels ( $\mathrm{TV}$, newspapers, radio), a sizable minority of producers view the Internet as a challenge to the gate-keeping of old media and say their users come to their sites for an alternative and more open perspective. However, this view needs to be balanced against the experiences of a number of young people and findings from our survey of sites, which suggest that a large number of civic websites for youth still maintain a strong gate-keeping function, albeit sometimes with different agendas (e.g., quality control, safeguarding users) and with a more diverse set of content producers than mainstream media.

Our research suggests that producers of political and civic websites need to give much more thought to 
how they spend their money. Significant amounts of funding are sometimes allocated to website designand especially to interactive features-without a clear conception of their function. While such features might make the organization look good, a large and complex site is not necessarily better for users. As some of the young people in our research suggested, it is important that sites are "fit to purpose." This means looking beyond the latest gimmicks and beyond some politically correct sense that an organization lives or dies by its website.

\section{Motivating Civic and Political Participation}

We found few cases in our interviews of attractive website design or the latest interactive features motivating civic engagement and participation in themselves. This counters a familiar and entrenched view that by amusing and entertaining young people (on the Internet and elsewhere) one can attract their attention and encourage them to become engaged in civic initiatives. The most significant characteristic of the civic and political engagement we found among the focus groups, as discussed by Gerodimos (2008, 2009) and by Miegel and Olsson (2010) in this issue of IJLM, is that it tends to focus predominantly on issues of immediate proximity for the participants. Individual and group identities, a sense of discrimination, and/or current life situation are key.

Thus, civic and political interests are related, in a number of cases, to having a family and/or close community of relatives or friends interested in the same issues and concerns. In a number of cases, local civic achievements-such as the experiences of group solidarity and of being active together and the feeling of having organized an event or campaign and received some positive feedback from peers or older adultsseem to generate a sense of efficacy that encourages and motivates further participation (whether online or offline). On the other hand, the results of offline active citizenship were frequently called into doubt by young people who had experienced governments' failure to respond-for example, when they had demonstrated in large numbers against university tuition fees and for better housing provision, or against the war in Iraq. Although such seemingly "unsuccessful" protests might sap the motivation to participate, for some the resulting anger led to further participation. In most of our focus groups, when young people were involved in civic activities that were related to their immediate contexts (both on- and offline), they seemed to feel more confident in their capacity to bring about change.

Without a "live" issue or social and political context for young people to engage with, even the bestdesigned and best-funded sites are likely to remain underutilized. However, from young people's perspectives, civic participation appears to be most successful when it is both peer-to-peer and enables opportunities for reciprocal engagement with those in power (Coleman 2008). Most youth civic organizations tend to offer one or the other, and when engagement with politicians is offered it is most often not reciprocal. This can be seen as a disincentive for young people to engage with formal politics online. As one young woman in our focus groups asked, "Why should we speak if no-one is listening?"

A majority of civic website producers in our sample did not see the Internet civic sphere as a replacement for offline civic and political actions but as a complement to them. For many, engagement still begins and ends offline. The Internet sustains and contributes to such engagement. The notion that online civic action and offline civic action reside in separate realms with separate participants was much debated but ultimately was regarded by many as untenable. Many of the producers we interviewed were at pains to explicitly connect online and offline politics and civic action, suggesting that they were never quite certain about the status of actions that took place solely online.

Nevertheless, signing online petitions or forwarding letters to big corporations-termed "one-click activism" by one producer and "feel-good activism" by another-are not necessarily seen to be the be-all and end-all of the things that young people are motivated to do online. Most civic producers view the information gathering necessary for making up one's mind about a particular cause or the meeting up, discussion, and protest offline as being supported and enhanced rather than replaced by the online actions offered in polls or forums. This is confirmed by focus group discussions with young people who connected their offline and online participation and did not see the Internet as an entirely separate sphere but as feeding into offline organizations in the areas of formal politics, music, environmentalism, or other campaigning. As this implies, offline civic-based or politically sympathetic friendship and comradeship can be strengthened and complemented online. 


\section{Understanding Context}

Inevitably for a cross-national study, we identified issues that were particularly acute or took on different forms at particular historical moments in different countries. For example, the sphere of politics is generally seen as dirty and corrupt in both Hungary and Slovenia, where respondents showed a clear predisposition toward detaching civic organizations from politics. This means that voting is not generally encouraged by youth civic sites in these countries and that even party sites attempt to steer clear of connections with politics.

Crucially for those interested in European civic identity (see Tuzzi, Padovani, and Nesti 2007), the notion of European citizenship and belonging is viewed in hugely different ways by young people in, for instance, Turkey, Slovenia, and the United Kingdom, where civic websites addressing European youth issues, travel, and integration are found more or less appealing. In the United Kingdom, for example, findings from focus groups with young people suggest that European identity is not at all valued or highly developed, except among a small minority of politically left-wing and antiauthoritarian youth who see it as a positive identity that supersedes the national one, which is seen as retrograde. In Slovenia, on the contrary, our research found some degree of positive feeling toward the idea of European citizenship among a wider range of youth. Most focus group participants displayed either a lack of knowledge of European politics or a sense of distrust about them. Many interviewees also seemed to lose any sense of motivation and affiliation toward politics and the civic sphere (which we could sometimes sense at the national levels and which was even clearer at the local and regional levels) when discussing Europe.

Most of the civic or political participation and engagement-sustained engagement in particulardescribed and identified across the focus groups appeared to begin and end offline in real communities or communities of interest and identity, even if the Internet explicitly provided a space, tool, or focal point for aspects of this engagement. Some civic sites may be set up as a short-term solution to a problem rather than being integrated into other activities-for instance, to prevent the demolition of a skate park or to inform young people about their voting rights. Such sites are often not heavily used over an extended period of time and are thus unlike those sites that have more diffuse motivations, such as gathering together a community of young people who are linked by common bonds. Websites formed by "specialist" groups (based on religious, cultural or subcultural identity, or locality) for highly specific audiences among young people and produced by members of that specific group (particularly by young members of the group) tend to support a stronger sense of belonging and community and are more likely to be used by members of the target group.

\section{New Politics Online?}

Although these points might seem to suggest that the forms of politics taking place online include nothing new, the evidence shows that, to the contrary, civic websites for young people are tapping into newer forms of civic and political participation. This is most apparent in the case of so-called ethical consumption or socially conscious shopping, which plays on the Internet's qualities as a medium of shopping and marketing par excellence (see Hirzalla and Van Zoonen 2010 in this issue of IJLM). Questions remain, however, about whether and how such activities are linked to traditional or more activist forms of political participation (Banaji and Buckingham 2009). We have found further interesting exceptions where the Internet does seem to make a clear difference to individuals or groups of young people in terms of engagement with the wider, interlinked civic and political spheres. For example, in a number of our partner countries the Internet was used by groups of young people as an alternative to mainstream media, as a means of accessing perspectives and information not found in traditional press or broadcasting. How this relates to action is still an open question, but the significance of having a freer flow of information and a less rigid hierarchy dictating who can express and broadcast political ideas online should not be downplayed. In countries where the authorities have begun to censor and regulate the online sphere-such as Turkey-the loss of this freedom highlights its importance still further.

We have also found evidence that the Internet can enable young people to take on and refine their role as monitorial citizens-for instance, by tracking elections; keeping abreast of privacy issues; discussing, photographing, and publicizing police behavior; debating civil liberties; and getting behind the scenes in conflict situations. As highlighted by Miegel and 
Olsson (2010), in special cases such as file-sharing and the free downloading of music, the Internet itself can be the focus of and reason for civic action. Young people who take part in such civic actions are not always from among those already or necessarily active in civic or political campaigns offline.

\section{Conclusion: Future Challenges}

CivicWeb was designed in the age of what is now commonly known as Web 1.0-with a general idea of the World Wide Web as a matter of individual or linked sites that would be put up largely by organizations, often with considerable funding behind them, almost as a kind of advertising for the work they were doing. To a large extent, this can be seen to reflect an old "mass media" model. The work of Montgomery and her team (2004) describing youth civic organizations online in the United States accorded with this approach, as did previous work on political young people using civic websites in Sweden (Olsson 2007) and the United Kingdom (Gerodimos 2008). In the interim, however, networks that are more interactive and "social" have emerged on the Web. Although we ought to be skeptical of the overly optimistic view of the possibilities of so-called Web 2.0, instant messaging and social networking sites like MySpace and Facebook, as well as wikis and other kinds of "social software," do represent a significant shift and offer different possibilities for participation in particular.

Even so, these new developments raise difficult methodological issues for future research. How do we best find instances of civic activity in the breadth and depth of MySpace or Facebook, for example? What would a sample consist of, and how might it be identified? CivicWeb addressed some of these issues, but only in the context of material put up by more-or-less formal or already-constituted social/political groups. Trying to track civic and political participation in domains like Facebook is increasingly important but also hugely complex.

This leads to a second issue that has continued to trouble us throughout our project: the meaning of civic and its relation to seemingly cognate terms such as political or social. As we found, the word civic does not simply translate across national contexts. Some languages have no obvious parallel term. Even in the literature in English, the criteria for defining what counts as "civic" vary widely. In some cases, the word appears to be a synonym (or even a euphemism) for politics.
In others, it seems to be something prepolitical, a kind of engagement that is about collective rather than individual identifications-albeit ones that are not yet articulated in political or adversarial terms. In yet other cases, civic seems to be much more nebulous or expansive: volunteering to help the elderly or picking up litter in the street becomes civic, and these activities in turn constitute what many people think of as being a "good citizen." Is the discursive meaning of civic the same as civil (as in "civil society"), with which it shares an etymology, or is civic more affiliated with citizenship (which itself has several competing definitions nested in several different rhetorical and political traditions)? In seeking to define civic, commentators often seem to make recourse to the notion of "common good"-but who defines the common good, and who is excluded when we define civic in this way (Banaji 2008)?

These questions have raised some serious methodological dilemmas-for example, about what to include or exclude from the samples of websites and groups being researched for CivicWeb. Should we include Christian or Muslim sites as civic sites? Many things that go on in religious communities and hence on religious sites might be called "civic." What of extreme right-wing sites: much of the rhetoric on these sites involves claims to be on the side of civic virtue and the common good (with the common good being defined in terms of ethnic and national purity). These sites also invite participation, and regulation on them is often similar to that encountered on more mainstream sites. Can such sites be termed "civic"?

Pushing this question further, we have found it necessary to ask what counts as civic participation. Many kinds of social participation exist, and some forms of participation that young people engage in are not recognized by adults, while other forms are positively denigrated or seen as threatening (Westheimer and Kahne 2004). So, do we count, for example, so-called ethical consumption as civic participation (Scammell 2000; Banaji and Buckingham 2009)? Is signing an online petition or responding to someone on a message board civic participation? Is smashing the windscreen of an SUV or setting fire to a vivisection lab civic participation? To push this argument to its limit, can terrorism in the interest of particular political causes constitute a form of civic participation?

Behind this is the danger that-far from encouraging civic participation-some online activity becomes a substitute for it. Thus, the argument runs, brief and episodic participation via email petitions, Facebook profiles, 
or message boards allows us to feel good about having done something, even to feel "empowered," but does such "participation" make much difference to the world? Young people are repeatedly encouraged to "have their say," but our project has found little evidence that people in positions of power are listening in a systematic and respectful manner-or, if they are, that they are doing anything in response. The superficial appearance of participation can easily justify recourse to a kind of cynicism.

Finally, there is a danger of assuming that participation is always a good thing in itself-that it is necessarily better than nonparticipation and that young people are somehow at fault if they choose not to participate (see Coleman 2005, 2008). If we consider some of the more confrontational and abusive ways people interact online, or some of the forms of offline participation that such behavior may lead to (such as racist violence), can we really be so sure that participation is always a good thing (Banaji 2008)? While we should avoid a wholesale relativism, avoiding normative assumptions about what responsible young people should be doing seems critically important. In the academic and policy literature in this area-and indeed on the websites themselves-we find a dominant conception of what young people should be doing that is not so different from the conceptions that dominated debates about offline participation in a pre-Internet age. We find implicit rules about good behavior, implicit constructions of identity, a favoring of certain kinds of responsible or "pro-social" orientations-all of which are embedded in the designs of websites, in how young people are addressed, in the kinds of (limited) participation that are invited, and in the way actual participation on the sites is moderated. Additionally, in particular national contexts across our project we found further disavowals - for instance of religion or politics-or specific affiliations that need to be made to support particular national civic identities. The problem with this normative view is that certain kinds of activity do not get recognized as civic, or as in any way valuable; more particularly, certain people's modes of expression-the styles of participation that are preferred by particular social groups-tend to be ignored or marginalized (Gerodimos 2009).

Our research shows that although the Internet is an excellent tool at the disposal of those already interested in politics, it is much less effective in reaching out to and engaging those who are not already engaged. This is partly because of the nature of the medium and partly because those who are less likely to be engaged are also those who are less likely to enjoy good access to the medium-and although that is changing, Internet provision is still largely governed by the logic of the market, which is primarily to target those who are already well served (Warschauer 2003; Fairlie 2006). Likewise, most civic sites are addressed to those who are already engaged, as is apparent in their implicit assumptions about what prospective visitors know, what they are likely to be interested in, and what is likely to motivate them. Casual visitors-and, perhaps, less well-educated, less middleclass visitors - are far less likely to be addressed or drawn in. The rhetoric of the websites in question is self-confirming, a matter of preaching to the converted. Thus, the Internet might actually reinforce particular forms of exclusion; it might become a forum where young people are invited to participate, but only if they follow rules set by those already in power and only if they behave according to certain middle-class norms of responsibility and good manners. And this is an invitation that some young people may well decide to refuse.

In light of this, the fundamental question that informed our research-and that has informed the wider debate in this area-ought to be rephrased. The question is not so much "Can the Internet reengage young people or enable them to participate when they were not participating before?" Rather, the question is "How might the Internet engage with other movements within society, or how might those other movements use technology, to bring about change?" The question thus becomes not about technology but about social and cultural processes.

\section{Acknowledgments}

The research discussed in this article (and in the other articles in this issue of IJLM) was made possible by funding from the European Commission under the Framework 6 program. We thank the civic and political producers who participated in our research and the young people whose insights and input made the research so interesting. The overall findings discussed in this article are the collective work of our seven teams in the United Kingdom, the Netherlands, Slovenia, Hungary, Spain, Turkey, and Sweden. All the reports referred to in this article are available for download at http://www.civicweb.eu/.

\section{References}

Bachen, C., C. Raphael, K. M. Lynn, K. McKee, and J. Philippi. 2008. Civic engagement, pedagogy, and information 
technology on Web sites for youth. Political Communication 25 (3):290-310. http://dx.doi.org/10.1080/ 10584600802197525 (accessed May 9, 2010).

Banaji, S. 2008. The trouble with civic: A snapshot of young people's civic and political engagements in twenty-first century democracies. Journal of Youth Studies 11 (5):54360. http://dx.doi.org/10.1080/13676260802283008 (accessed May 10, 2010).

Banaji, S., and D. Buckingham. 2009. The civic sell: Young people, the Internet and ethical consumption. Information, Communication and Society 12 (8):1197-223. http:// www.informaworld.com/smpp/content $\sim \mathrm{db}=\mathrm{all}$ ? content $=$ 10.1080/13691180802687621 (accessed May 9, 2010).

Bennett, W. L. 2003. New media power: The Internet and global activism. In Contesting media power: Alternative media in a networked world, ed. N. Couldry and J. Curran, 17-36. Lanham, MD: Rowman and Littlefield.

Bennett, W. L., ed. 2008. Civic life online: Learning how digital media can engage youth. Cambridge, MA: MIT Press.

Bennett, W. L., C. Wells, and D. G. Freelon. 2009. Communicating citizenship online: Models of civic learning in the youth Web sphere. Seattle: Center for Communication and Civic Engagement. http://www.engagedyouth.org/blog/wp-content/ uploads/2009/02/communicatingcitizeshiponlinecloreport .pdf (accessed August 2009).

Coleman, S. 2005. Remixing citizenship: Democracy and young people's use of the Internet. With C. Rowe. London: Carnegie Trust Young People's Initiative. http://cypi .carnegieuktrust.org.uk/files/Carnegie_v3LRES_0.pdf (accessed May 2, 2010).

Coleman, S. 2008. Doing it for themselves: Management versus autonomy in youth e-citizenship. In Civic life online: Learning how digital media can engage youth, ed. W. L. Bennett, 189-206. Cambridge, MA: MIT Press.

Dahlgren, P., ed. 2007. Young citizens and new media: Learning for democratic participation. London: Routledge.

Fabbro, Francesco. 2010. Interactivity as ideological dilemma: A socially situated reading of interactivity discourse in three civic sites in the Italian context. IJLM 2 (1): 81-93. http://dx.doi.org/10.1162/IJLM_a_00043.

Fairlie, R. 2006. Crossing the divide: Immigrant youth and digital disparity in California. Santa Cruz: Center for Justice, Tolerance and Community, University of California, Santa Cruz. http://www2.ucsc.edu/cjtc/docs/digital.pdf (accessed May 9, 2010).

Galston, W. A. 2004. Civic education and political participation. PS: Political Science and Politics, April. http://www .apsanet.org/imgtest/CivicEdPoliticalParticipation.pdf (accessed May 9, 2010).

Gerodimos, R. 2008. Mobilising young citizens in the UK: A content analysis of youth and issue websites. Information, Communication and Society 11 (7):964-88. http://dx.doi.org/ 10.1080/13691180802109014 (accessed May 10, 2010).

Gerodimos, R. 2009. New media, new citizens: Youth attitudes towards online civic engagement. In Proceedings of the WebSci'09: Society on-line, 18-20 March 2009, Athens, Greece. http://journal.webscience.org/182/ (accessed May 9, 2010).
Gibson, R., P. Nixon, and S. Ward, eds. 2003. Political parties and the Internet. London: Routledge.

Hirzalla, Fadi, and Liesbet Van Zoonen. 2010. Affective political marketing online: Emotionality in the youth sites of Greenpeace and WWF. IJLM 2 (1):39-54. http://dx.doi.org/10.1162/IJLM_a_00040.

Kann, M., J. Berry, C. Gant, and P. Zager. 2007. The Internet and youth political participation. First Monday 12 (8). http://firstmonday.org/htbin/cgiwrap/bin/ojs/index .php/fm/article/view/1977/1852 (accessed May 9, 2010).

Lenhart, A., D. Fallows, and J. Horrigan. 2004. Content creation online: The Pew Internet and American Life Project. http://www.pewinternet.org/Reports/2004/Content -Creation-Online.aspx (accessed May 9, 2010).

Loader, B., ed. 2007. Young citizens in the digital age. London: Routledge.

Miegel, Fredrik, and Tobias Olsson. 2010. Surveillance and file-sharing: Two issues engaging the unengaged. IJLM 2 (1):55-66. http://dx.doi.org/10.1162/IJLM_a_00041.

Montgomery, K., B. Gottlieb-Robles, and G. O. Larson. 2004. Youth as e-citizens: Engaging the digital generation. Executive summary. Washington, DC: Center for Social Media, American University. http://www.centerfor socialmedia.org/ecitizens/execsumm.pdf (accessed October 2008).

Olsson, T. 2007. An indispensable resource: The Internet and young civic engagement. In Young citizens and new media: Learning for democratic participation, ed. P. Dahlgren, 187204. London: Routledge.

Putnam, R. 2000. Bowling alone: The collapse and revival of American community. New York: Simon and Schuster.

Scammell, M. 2000. The Internet and civic engagement: The age of the citizen consumer. Political Communication 17 (4):351-55. http://dx.doi.org/10.1080/10584600050178951 (accessed May 10, 2010).

Scheufele, D., and M. Nisbet. 2002. Being a citizen online: New opportunities and dead ends. Press/Politics 7 (3):5575. http://hij.sagepub.com/cgi/content/short/7/3/55 (accessed May 10, 2010).

Szakács, Judit, and Éva Bognár. 2010. Making sense of Zhoriben: The story of a Romani social networking site in Hungary. IJLM 2 (1):67-80. http://dx.doi.org/10.1162/IJLM_a_00042.

Tuzzi, A., C. Padovani, and G. Nesti. 2007. Communication and (e)democracy: Assessing European e-democracy discourses. In Reclaiming the media: Communication rights and democratic media roles, ed. B. Cammaerts and N. Carpentier, 31-65. Bristol, UK: Intellect.

Warschauer, M. 2003. Technology and social inclusion. Cambridge, MA: MIT Press.

Westheimer, J., and J. Kahne. 2004. Educating the good citizen: Political choices and pedagogic goals. PS: Political Science and Politics, April. http://www.democraticdialogue.com/ DDpdfs/WestheimerKahnePS.pdf (accessed August 3, 2009).

Zukin, C., S. Keeter, M. Andolina, K. Jenkins, and M. X. Delli Carpini. 2006. A new engagement? Political participation, civic life, and the changing American citizen. Oxford: Oxford University Press. 